\title{
Factors affecting excitatory amino acid release following severe human head injury
}

\section{Ross Bullock, M.D., Ph.D., Alois Zauner, M.D., John J. Woodward, Ph.D., John Myseros, M.D., Sung C. Choi, Ph.D., John D. Ward, M.D., Anthony Marmarou, Ph.D., and Harold F. Young, M.D. \\ Division of Neurosurgery and Departments of Pharmacology and Biostatistics, Medical College of Virginia, Virginia Commonwealth University, Richmond, Virginia}

Recent animal studies demonstrate that excitatory amino acids (EAAs) play a major role in neuronal damage after brain trauma and ischemia. However, the role of EAAs in patients who have suffered severe head injury is not understood. Excess quantities of glutamate in the extracellular space may lead to uncontrolled shifts of sodium, potassium, and calcium, disrupting ionic homeostasis, which may lead to severe cell swelling and cell death. The authors evaluated the role of EEAs in human traumatic brain injury.

In 80 consecutive severely head injured patients, a microdialysis probe was placed into the gray matter along with a ventriculostomy catheter or an intracranial pressure (ICP) monitor for 4 days. Levels of EAAs and structural amino acids were analyzed using high-performance liquid chromatography. Multifactorial analysis of the amino acid pattern was performed and its correlations with clinical parameters and outcome were tested. The levels of EAAs were increased up to 50 times normal in $30 \%$ of the patients and were significantly correlated to levels of structural amino acids both in each patient and across the whole group $(\mathrm{p}<0.01)$. Secondary ischemic brain injury and focal contusions were most strongly associated with high EAA levels (27 $\pm 22 \mu \mathrm{mol} / \mathrm{L}$ ). Sustained high ICP and poor outcome were significantly correlated to high levels of EAAs (glutamate $>20 \mu \mathrm{mol} / \mathrm{L} ; \mathrm{p}<0.01$ ).

The release of EAAs is closely linked to the release of structural amino acids and may thus reflect nonspecific development of membrane micropores, rather than presynaptic neuronal vesicular exocytosis. The magnitude of EAA release in patients with focal contusions and ischemic events may be sufficient to exacerbate neuronal damage, and these patients may be the best candidates for treatment with glutamate antagonists in the future.

Key Words * severe head injury * microdialysis * glutamate * intracranial pressure * outcome * glutamate antagonist

Glutamate is the most widely distributed excitatory neurotransmitter in the mammalian brain. $[3,6,10,11,17,22,49]$ Following the comparatively recent discovery of this role, it has become a focus of major neuroscientific interest because of its potential role in the causation of both acute and chronic neuronal damage. In 1983, Rothman and Olney[46] proposed the "excitotoxic" hypothesis. This hypothesis was based on previous studies that showed the neurotoxic potential of glutamate and its coagonist aspartate in the normal brain and, more recently, in tissue cultures.[2,3,8,9,15,28] At least four glutamate receptor subtypes exist on different parts of mammalian neurons, and now extensive studies have characterized the responses of these receptors to glutamate and its coagonists (including aspartate and glycine).[3,12,17,20,23,26,29,35,46,53,54] 
Many of the normal physiological processes of the cortex and the hippocampus, in particular, are thought to depend on this neurotransmitter function of glutamate.[15,30,31,46]

However, when glutamate is present in excessive quantities, it may overactivate specific ion channels, especially the N-methyl-D-aspartate channel. This results in uncontrolled entry of sodium and calcium into cells along with associated potassium egress into the extracellular space. When this process is rapid, it can result in massive accumulation of intracellular calcium with rapid neuronal death--"fast excitotoxicity."[43,50] This produces neuronal histological appearances that are identical to those seen after ischemic events.[1,18,19,21,50,51] When the entry of calcium is slowed, a "delayed neuronal death" can result in the delayed disappearance of neurons, anywhere from 5 to 7 days after the event.[10,44,45]

A potassium shift into the extracellular space will result in rapid swelling of astrocytes, which absorb quantities of potassium to preserve ionic homeostasis.[2,10,28] This process may cause rapid "cytotoxic edema," which is probably a major factor in causation of posttraumatic raised intracranial pressure (ICP).

Recent studies in which the microdialysis technique has been used have shown that large quantities of glutamate are released into the extracellular space in animal models of both neurotrauma and stroke.[3,6,11,22,23,43,49] In these models, a variety of drugs that block the effects of glutamate both presynaptically and at postsynaptic receptor sites have reduced both ischemic brain damage and glutamate release. $[5,7,12,20,21,24,25,29,32,33,36,40,53,55,56]$

There are now several Phase II and Phase III trials in progress to evaluate the efficacy of glutamate antagonist drugs in both neurotrauma and stroke. However, the pattern of glutamate release after neurotrauma has hitherto only been documented in the cerebrospinal fluid and in small numbers of patients by using the microdialysis technique. $[9,10,15,23,44]$ We have therefore prospectively studied 80 patients by using intracerebral microdialysis to address the following hypotheses: 1) release of excitatory amino acids (EAAs) is a significant event after human traumatic brain injury (TBI);2) the magnitude of EAA release in these patients is sufficient to account for neuronal damage in accordance with the excitotoxic hypothesis; and 3) the EAA release after trauma may be exacerbated by secondary ischemic events such as low cerebral perfusion (CPP), high ICP, and hypoxemic events.

\section{CLINICAL MATERIAL AND METHODS}

These studies were approved by the Committee for Conduct of Human Research of the Medical College of Virginia and Virginia Commonwealth University. In 80 consecutive severely head injured patients admitted to the intensive care unit (ICU) at the Medical College of Virginia, from whom consent was obtained for microdialysis and intensive neuromonitoring studies, microdialysis probes were placed within the cerebral cortex in accordance with an established protocol. The patients received standard aggressive management that included rapid removal of intracranial hematomas, ICP monitoring performed by ventriculostomy, and careful management of ICP by means of artificial ventilation, neuromuscular paralysis, mannitol ventricular drainage, and, in a few patients with uncontrolled high ICP, barbiturate infusion or induction of moderate hypothermia. In 63 patients, regional cerebral blood flow (CBF) measurements were made during or immediately before the microdialysis was begun.

\section{Microdialysis Procedure}

We used custom-made, commercially produced microdialysis probes, with a molecular weight cutoff of 20,000 D and a 10-mm active dialysis surface. The probes were sterilized using low-temperature, long-cycle ethylene oxide gas and implanted in one of two ways. In patients who had diffuse injuries and who did not undergo craniotomy, the probes were inserted using the same twist-drill hole that had been used for ventriculostomy in the ICU. In $60 \%$ of these patients the probe was secured via a triple lumen transcranial 
bolt, as described earlier by our group.[58] In patients who had focal mass lesions and who underwent a craniotomy, the probes were placed into the cortex, under direct vision, at the evacuated hematoma site, adjacent to a removed or unremoved contusion (Fig. 1).

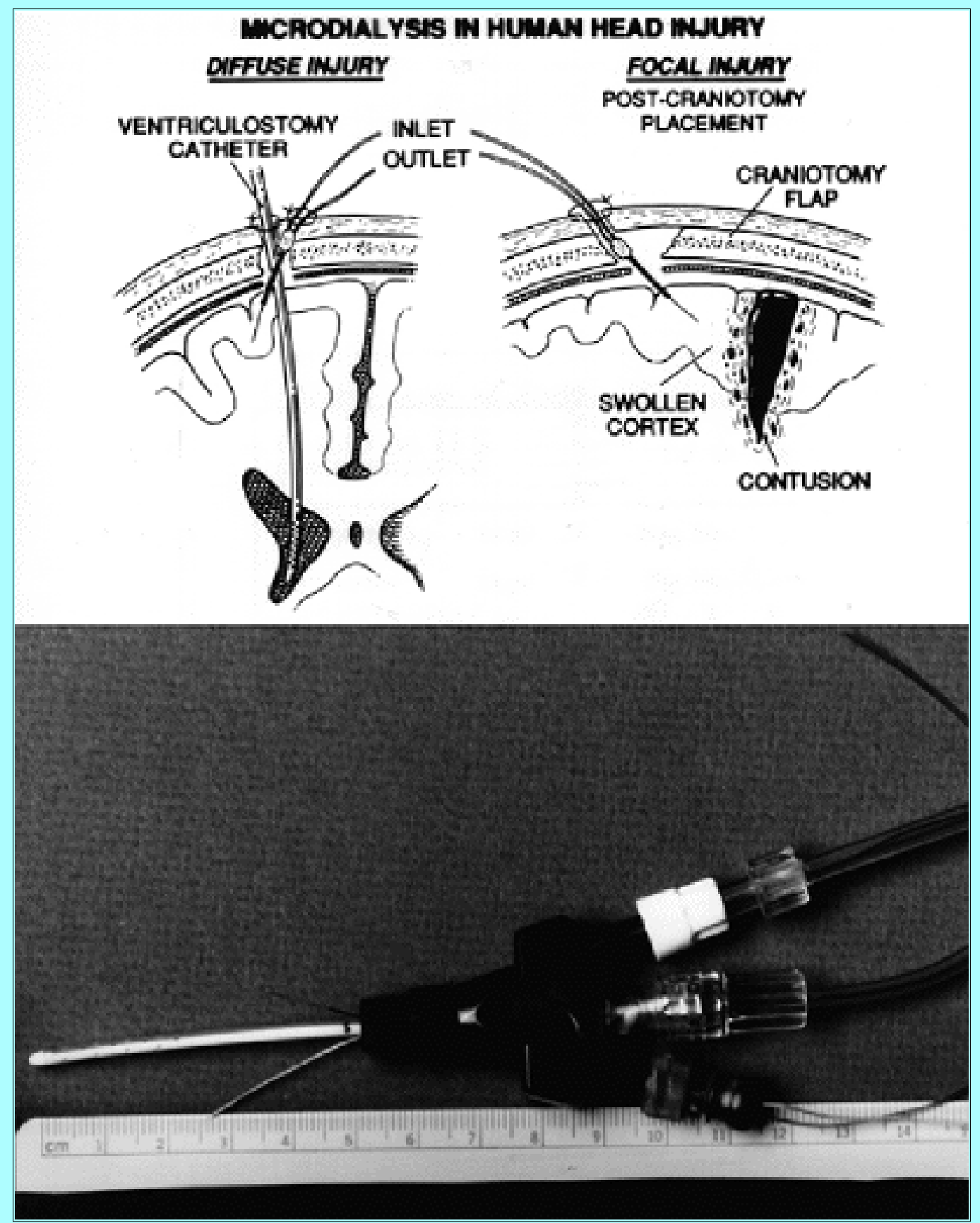

Fig. 1. Upper: Diagram showin insertion techniques used early in the study for placing the microdialysis probe in patients with diffuse and focal injuries. Lower: Photograph of a triple-lumen transcranial bolt for fixation of the microdialysis probe (top), along with an oxygen sensor (lower) used in the patients enrolled later in the study.

The probes were perfused with sterile $0.9 \%$ saline at $2 \mu \mathrm{l} /$ minute by means of a microdialysis pump. The efflux dialysate was collected using a computer-controlled, automated, refrigerated fraction collector, at 4 šC. Fractions $(60 \mu \mathrm{l})$ were collected every 30 minutes into labeled, sealed glass vials and frozen at $-70 \mathrm{~s} \mathrm{C}$, for later high-performance liquid chromatography (HPLC) analysis. Initially, every microdialysis probe was tested in vitro to measure the total recovery rates for the different analytes tested. Because the probe recovery rates were remarkably constant, this was subsequently performed for approximately every fifth patient only. 
Pilot studies indicated that "ischemic events" were an important factor influencing EAA release. Therefore, emergency department and clinical records and ICP, CPP, and regional CBF data were used to construct a five-point scoring system for significant ischemic events (Table 1).

\begin{tabular}{|c|c|}
\hline \multicolumn{2}{|c|}{$\begin{array}{c}\text { TABLE } 1 \\
\text { FIVE POINT SCORNG SVSTEMFOR DETECTNG ISCHEMIC } \\
\text { EVENTS IN HEAD-IN.JRED PATIENTS }\end{array}$} \\
\hline Event \& Criteria & Sc ore \\
\hline \multicolumn{2}{|l|}{ hypoxemia } \\
\hline $\begin{array}{l}\mathrm{PaOe} \times 60 \mathrm{~mm} \mathrm{Hg} \\
\text { hypotension }\end{array}$ & 1 \\
\hline $\begin{array}{l}\text { MA EP } \propto 50 \mathrm{~mm} \text { Hgt } \\
\text { hemispheric CBF }\end{array}$ & 1 \\
\hline $\begin{array}{l}\times 20 \mathrm{~m} .1100 \mathrm{~g}-1 \mathrm{~min} \\
\text { herniation }\end{array}$ & 1 \\
\hline $\begin{array}{l}\text { fined dilated pupil } \neq \\
\text { CPP }\end{array}$ & 1 \\
\hline$\times 50 \mathrm{~mm} \mathrm{Hg}$ for $>30 \mathrm{~min}$ & 1 \\
\hline \multicolumn{2}{|c|}{$\begin{array}{l}\text { * Individual scores are summed for a total of } 0 \text { to } 5 \text {. } \\
\dagger \text { For } 30 \text { minutes or more prior to resusitation. } \\
\ddagger \text { In the hemisphere used for microdial ysis. }\end{array}$} \\
\hline
\end{tabular}

\section{High-Performance Liquid Chromatography Analysis}

The concentration of amino acids in the microdialysis samples was measured using HPLC electrochemical detection after o-pthaldialdehyde/thiol derivatization.[34] Briefly, a refrigerated autosampler was used to mix $10 \mu \mathrm{l}$ of dialysate with $40 \mu \mathrm{l}$ of an o-pthaldialdehyde/thiol solution. Samples were allowed to react for 15 minutes before injection onto a liquid chromatograph on which derivatized amino acids were separated on an octadecyl-silane $(3-\mu \mathrm{m}) \mathrm{C} 18$ reverse-phase column. The mobile phase consisted of $0.1 \mathrm{M}$ phosphate, $2 \mathrm{mM}$ ethylenediamine tetraacetic acid, and 7\% acetonitrile at a $\mathrm{pH}$ of 5.85. Amino acids were detected on a thin-layer electrochemical cell with a glassy carbon electrode operated at $700 \mathrm{mV}$. The analog output of the detector cell was digitized and collected by a computer running chromatography software. Peak areas for each amino acid were converted to concentration by comparing them to known standards run at regular intervals.

\section{Statistical Analysis}

In all patients, physiological data such as ICP, CPP, mean arterial blood pressure (MABP), and clinical characteristics were logged into a VAX mainframe computer (Neurocore, Medical College of Virginia Database) and these data were time-locked with the biochemical data for excitatory and structural amino acids for analysis. The patients were subdivided on the basis of their glutamate data into three categories: low glutamate, less than $5 \mu \mathrm{mol} / \mathrm{L}$; intermediate glutamate, 5 to $20 \mu \mathrm{mol} / \mathrm{L}$; and high glutamate, more than 20 $\mu \mathrm{mol} / \mathrm{L}$. For each of these categories, correlations were sought with the following clinical features: 1) prior ischemic events, according to the ischemia score; 2) computerized tomography (CT) scanning category (hematoma, contusion, and diffuse injury); 3) MABP, ICP, and CPP; and 4) outcome.

For continuously measured variables, the intrapatient (within subject) correlations between glutamate and aspartate and structural amino acids were examined.[14] The relationships between glutamate and ICP, CPP, and MABP were tested using rank correlations. The relationships of mean glutamate, aspartate, and threonine with outcome, CT characteristics, and ischemic events were also tested. In addition, "threshold" analyses were performed by classifying patients into high- and low-glutamate groups, (> $20 \mu \mathrm{mol} / \mathrm{L}$ or $3 / 420 \mu \mathrm{mol} / \mathrm{L}$, respectively) and testing the relationship with categorical variables by using a chi-square test.

To test the strength of the correlations among different continuous variables across the entire group of 80 
patients, 80 intrapatient correlations were first determined for the variables glutamate, aspartate, threonine, ICP, and CPP. Spearman's correlation coefficient was used to represent the degree of the relationship in each patient. Data consisting of 80 independent correlation coefficients were found to be normally distributed and, therefore, a one-sample t-test was used to test the significance of the mean interpatient correlation.

\section{Sources of Supplies and Equipment}

The microdialysis probes (CMA 20 Custom Probes), the microdialysis pump (model CMA 15), the refrigerated fraction collector, and the refrigerated autosampler (model CMA 200) were manufactured by CMA Microdialysis (Acton, MA). Rainin Dynamix chromatography software, which was obtained from Rainin Instrument, Inc. (Woburn, MA), was used with a Macintosh computer obtained from Apple Computers (Cupertino, CA) in the HPLC analysis.

\section{RESULTS}

No complications were induced by the placement of the probes. In three patients, the probes needed to be removed and replaced due to rupture of the membrane. In one patient, a probe failed to recover analytes. These patients were excluded from the final analysis.

\section{Clinical Characteristics}

The clinical characteristics of the 80 patients described in this study are summarized in Table 2. Seventy-six patients were comatose on arrival and the overall mortality rate in the study was $29 \%$. In four patients, microdialysis was begun after they had deteriorated into the coma hours or days after injury.

\begin{tabular}{|c|c|c|c|}
\hline CLINICAL CHARACTERISTICS OF & $\begin{array}{l}\text { TABLE } 2 \\
80 \text { PATIEN } \\
\text { MATE LEV }\end{array}$ & $\begin{array}{l}\text { CATEGOREED } \\
\mathrm{S}^{\star}\end{array}$ & BV DIALYSATE \\
\hline & & Glutame & (9) \\
\hline Characteristics & Patients & $\leq 20 \mathrm{mmoll}$ & $>20 \mathrm{mmoll}$ \\
\hline $\operatorname{sex}$ & & & \\
\hline male & 56 & 48 & 22 \\
\hline $\begin{array}{l}\text { female } \\
\text { admission GCS category }\end{array}$ & 24 & 22 & 8 \\
\hline $3-4$ & 35 & 26 & 18 \\
\hline $5-6$ & 11 & 14 & 0 \\
\hline $7-8$ & 21 & 22 & 4 \\
\hline $9-11$ & 10 & 8 & 4 \\
\hline $12-15$ & 3 & 0 & 4 \\
\hline $\begin{array}{l}\text { W/craniotom y } \\
\text { ischemic ewents score }(0-50)\end{array}$ & 32 & 22 & 18 \\
\hline 0 & 22 & 20 & 8 \\
\hline 1 & 21 & 22 & 4 \\
\hline 2 & 10 & 10 & 2 \\
\hline 3 & 10 & 10 & 2 \\
\hline 4 & 11 & 6 & 8 \\
\hline 5 & 6 & 0 & 8 \\
\hline outcomet & & & \\
\hline $\begin{array}{l}\text { faworable } \\
\text { unfaworable }\end{array}$ & 43 & $\begin{array}{l}40 \\
18\end{array}$ & $\begin{array}{r}6 \\
36\end{array}$ \\
\hline
\end{tabular}

In 34 patients, microdialysis monitoring was performed at the border zone of a contusion and, in the majority of these cases, the contusion had been resected prior to placement of the microdialysis probe. The microdialysis probe was placed in the nonevocative cortex beneath a hematoma after it had been removed in 
14 patients with acute subdural hematomas and in five patients with epidural hematomas.

\section{In Vitro Calibration of the Microdialysis Probes and Methodological Errors}

The mean recovery rate for glutamate and aspartate was $43 \pm 4 \%$; the recovery rate for threonine was $22 \pm$ $1 \%$.

Whenever patients were disconnected from the microdialysis pump, accidentally or to obtain CT scans or be transported to the operating room, the amino acid concentration in the first microdialysis sample obtained after reconnection was found to be 50 to $100 \%$ higher than the previous or subsequent value. This is because the first postreconnection samples contained the dialysis fraction that had been standing in the microdialysis probe during the disconnection period. Theoretically, amino acids could equilibrate to $100 \%$ of the true extracellular fluid value. These samples were omitted from further data analysis.

\section{Relationship Between Glutamate and Aspartate}

When graphs of time-dependent changes in aspartate and glutamate within individual patients were studied, aspartate was seen to follow glutamate variations closely (Fig. 2).

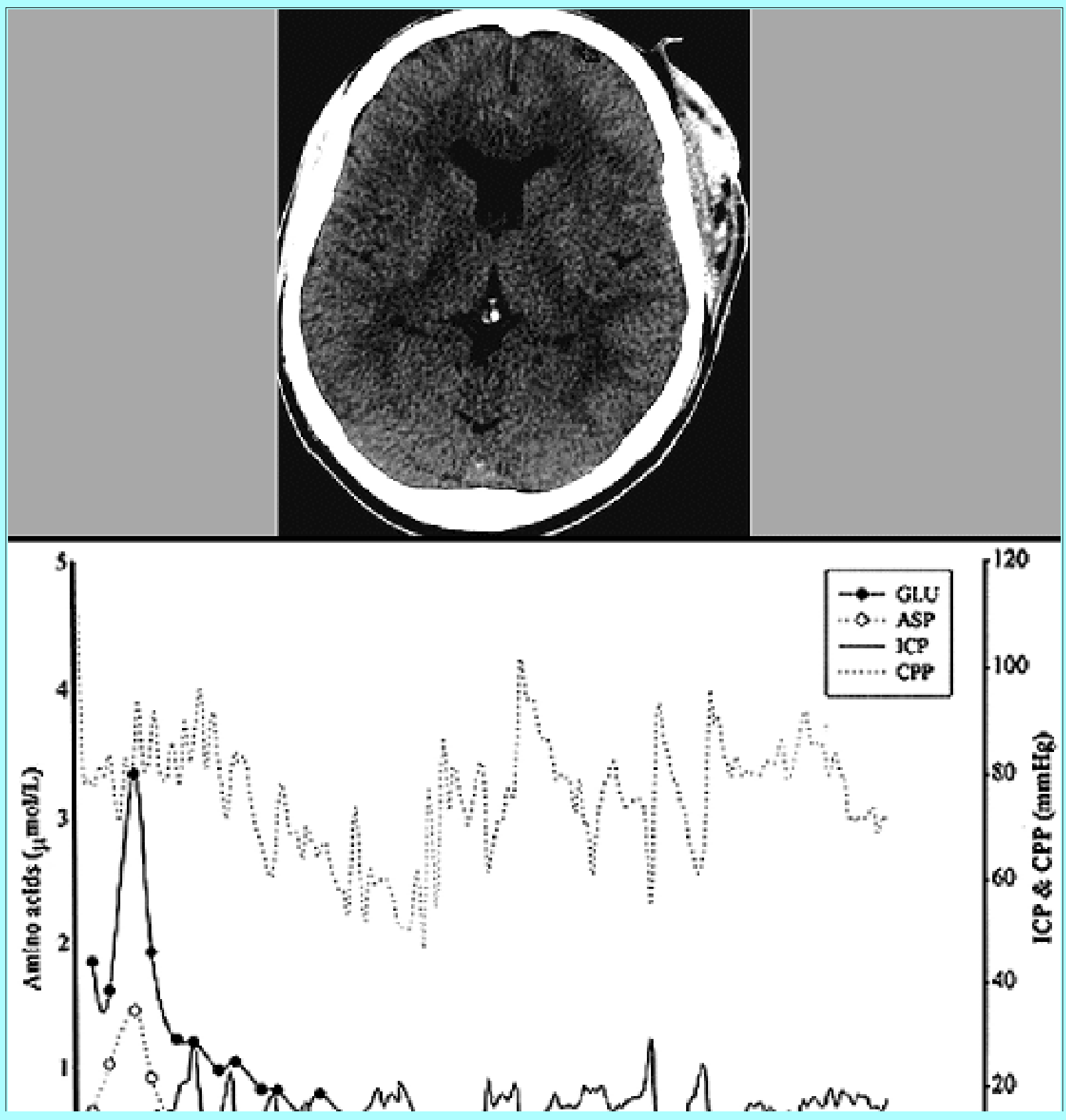




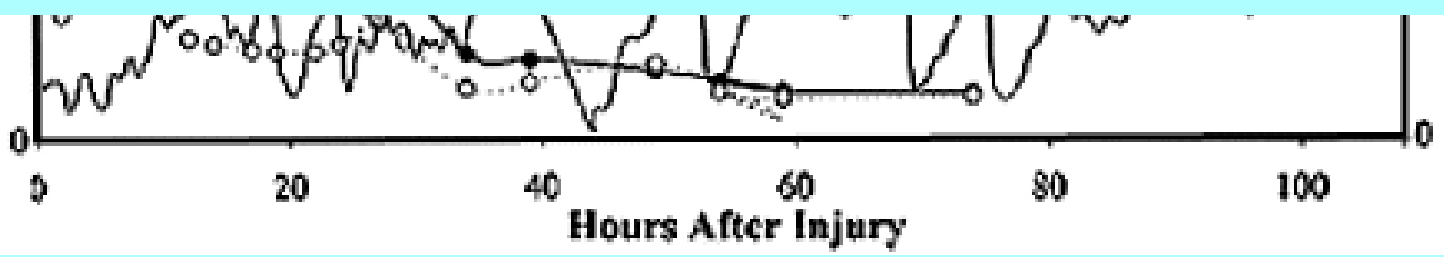

Fig. 2. Data obtained in a 24-year-old patient with diffuse injury. The relationships among the dialysate EEAs (glutamate [GLU] and aspartate [ASP]), ICP, and CPP are shown over time (normal glutamate level $<2 \mu \mathrm{mol} / \mathrm{L}$ ). Upper: Computerized tomography scan demonstrating the site of the microdialysis probe (arrow). Lower: Graph displaying measurements of GLU, ASP, ICP, and CPP. Note that the EEAs remained in the "normal range" during most of the monitoring period.

The mean correlation coefficient between glutamate and aspartate for the 80 patients studied was $0.683 \pm 0.21$ $(\mathrm{p}<0.01)$. Thus, factors affecting these two EAAs operated together in this patient group. The mean values for glutamate in different injury subtypes, in relation to the normal range reported for humans measured by microdialysis, is shown in Table 3.

\begin{tabular}{|c|c|c|c|c|}
\hline COMPARISON OF CT & $\begin{array}{l}\text { ID NGS W } \\
\text { ND STRUO }\end{array}$ & $\begin{array}{l}\text { ABLE } 3 \\
\text { H LEVELS OF } \\
\text { URAL AMINO }\end{array}$ & $\begin{array}{l}\text { AN DIALYSA } \\
\text { DS }\end{array}$ & XC TATORV \\
\hline CT Finding & $\begin{array}{l}\text { No. of } \\
\text { Patierts }\end{array}$ & $\begin{array}{l}\text { Glutamate } \\
\text { (mmolrt) }\end{array}$ & $\begin{array}{l}\text { Aspartate } \\
\text { (mmolr'L] }\end{array}$ & $\begin{array}{l}\text { Threonine } \\
\text { (mmolrt) }\end{array}$ \\
\hline $\begin{array}{l}\text { diffuse injury } \\
\text { contusion } \\
\text { subdural hematoma } \\
\text { epidural hematoma. }\end{array}$ & $\begin{array}{r}32 \\
29 \\
14 \\
5\end{array}$ & $\begin{aligned} 14.1 & \pm 7.7 \\
27 & \pm 20 \\
18 & \pm 15 \\
3 & \pm 3\end{aligned}$ & $\begin{array}{l}2.2 \pm 1.1 \\
8.3 \pm 4.5 \\
4.5 \pm 3.5 \\
0.4 \pm 0.2\end{array}$ & $\begin{array}{l}7.3 \pm 5.5 \\
9.5 \pm 6.5 \\
9.9 \pm 8.0 \\
6.8 \pm 7.8\end{array}$ \\
\hline
\end{tabular}

\section{Relationship Between EAAs and Structural Amino Acids}

In all patients a structural amino acid, either threonine (71 patients) or valine (nine patients), was measured. Structural amino acids were significantly correlated with EAAs $(r=0.59, \mathrm{p}<0.01)$ Although the relationship between structural amino acids and EAAs was remarkably constant within each patient throughout the clinical course, in some patients the former were released in higher concentrations than the latter and in others the reverse occurred. In general, patients with the highest levels of EAAs demonstrated structural amino acids levels that were even higher, whereas in some patients with intermediate levels of EAA release, the levels of EAAs exceeded those of structural amino acids. In no patient did structural amino acids rise or fall without concomitant changes in EAAs or vice versa.

\section{Changes in EAAs During Monitoring}

Four general patterns of EAA release could be recognized among these 80 patients. In patients with near-normal EAAs (Group 1), levels of glutamate, aspartate, and threonine tended to decline during the monitoring period, usually falling to within normal range by the end of the first 12 to 18 hours after injury (Fig. 2). These were most often patients in whom there was a normal CT appearance and no secondary ischemic event. In those patients with intermediate levels of EAAs (5-20 $\mu \mathrm{mol} / \mathrm{L}$; Group 2), more heterogeneous patterns of change with respect to time were seen. In most of these patients, there was a gradual decline in EAA levels over several days, although the levels of EAAs remained higher than normal for days (Fig. 3). Most of these patients were those who sustained ischemic events or experienced raised ICP during their early postinjury course. In 30\% of Group 2 patients, EAA release remained constant and moderately elevated throughout the monitoring period. In none of these patients was a progressive rise in EAAs detected. 


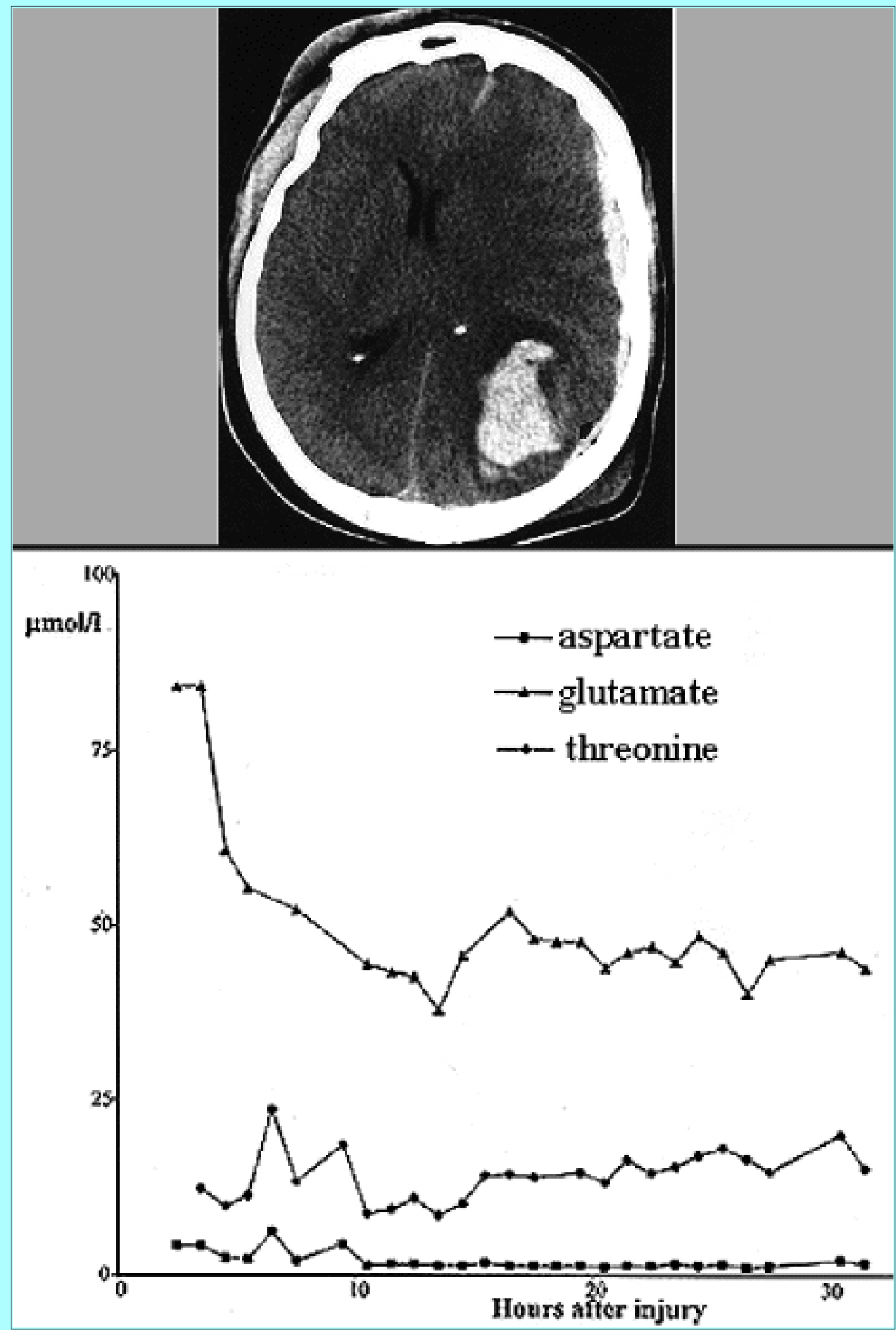

Fig. 3. Data showing typical "decline and stable baseline" pattern of very high EAAs in a patient with focal contusions at the probe placement site. The patient made a good recovery. Upper: Preoperative CT scan showing a right hemisphere subdural hematoma and focal hemorrhagic contusion. The microdialysis probe was placed in position (arrow) after the hemorrhagic contusion was evacuated. Lower: Graph displaying the pattern of dialysate EAA and structural amino acid changes over 30 hours of monitoring. Note that glutamate was approximately 25 times higher than normal, which is $2 \mu \mathrm{mol} / \mathrm{L}$. 
Patients with an extracellular fluid glutamate greater than $20 \mu \mathrm{mol} / \mathrm{L}$ (Group 3) demonstrated the most heterogeneous changes in EAAs over time. In $42 \%$ of this group, the EAAs were seen to rise progressively and, in most of these patients, elevated ICP were present along with significantly reduced CPP $(<50 \mathrm{~mm} \mathrm{Hg})$. In the majority of these patients, death was the outcome. In all these patients, prior ischemic events or elevated ICP was present. Thus, a progressively rising level of EAAs was not seen, except in patients who eventually died. In four patients in the entire series, all members of Group 3, a massive increase in EAAs and structural amino acids was seen superimposed on a relatively constant base line (Fig. 4). In none of these four patients could a hemodynamic explanation for this sudden increase be found. In all four, however, the microdialysis probe was close to a cerebral contusion or intracerebral hematoma. In the remaining 12 patients in Group 3, the EAAs exhibited a progressively downward trend, but remained far above the normal range for several days.

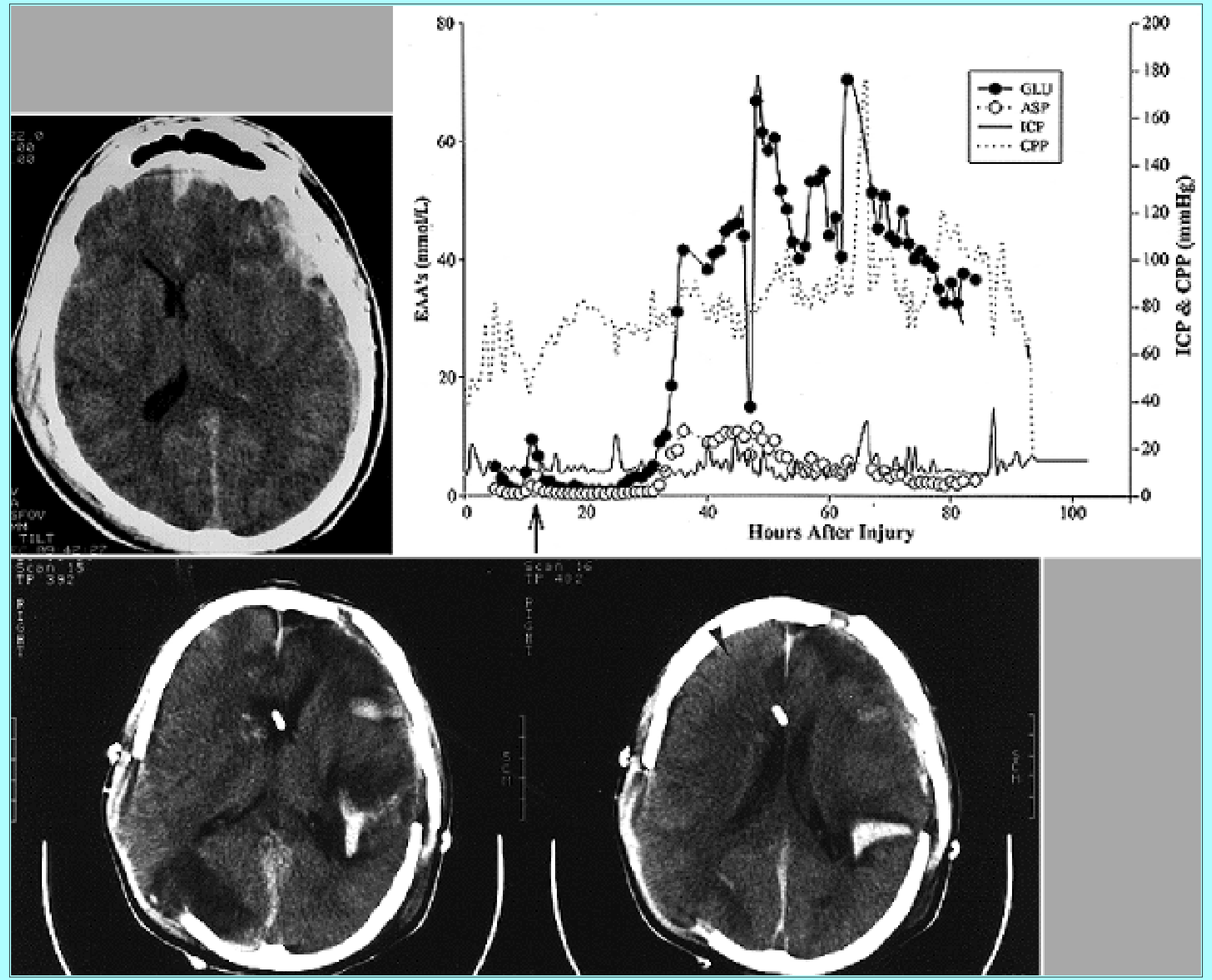

Fig. 4. Data documenting a marked sustained rise in dialysate EAAs in a patient with acute subdural hematoma and delayed epidural and intracerebral hematomas, who underwent two craniotomies. The patient remains vegetative at 3 years postinjury. Upper Left: Initial CT scan showing the acute subdural hematoma. Lower: Postoperative CT scan obtained after second 
craniotomy, showing widespread bilateral damage; arrow indicates approximate probe site. Upper Right: Graph showing levels of dialysate EAAs, ICP, and CPP. Note the small (fivefold) increase in glutamate at the time of the epidural hematoma (arrow). There was an unexplained massive delayed EAA rise 32 hours after injury, which was unassociated with ICP, CPP, or $\mathrm{PaO}_{2}$ changes.

With the exception of the four patients just mentioned, the hour-to-hour variation in levels of EAAs and threonine, as measured in the study, was 10 to $20 \%$ above or below baseline. This variability was remarkably constant in all categories of patients. Thus, with the exception of four patients, the magnitude and pattern of EAA release was apparent from the first 12 to 24 hours of microdialysis.

\section{Relationship Between EAAs and Clinical Injury Subtypes}

Tables 3 and 4 and Fig. 5 show the relationship between the major head injury CT diagnostic categories and EAA and structural amino acid release.

\begin{tabular}{|c|c|c|c|c|}
\hline EFFECT OF ISCl & $\begin{array}{l}\text { MIC EVENTSO } \\
\text { BV CT }\end{array}$ & $\begin{array}{l}\text { TABLE } 4 \\
\text { EVELS OF DIAL } \\
\text { ION CLASSF K }\end{array}$ & $\begin{array}{l}\text { SATE GLUTAM } \\
\text { TION太 }\end{array}$ & E SUBDIYDED \\
\hline & & Mean Glutam & te (mmoll' L) & \\
\hline $\begin{array}{l}\text { Secondary } \\
\text { Insult }\end{array}$ & $\begin{array}{l}\text { Diffuse } \\
\text { Iri ury }\end{array}$ & $\begin{array}{l}\text { Corktu- } \\
\text { sion }\end{array}$ & $\mathrm{SDH}$ & $\mathrm{EDH}$ \\
\hline $\begin{array}{l}\text { present } \\
\text { absent } \\
\text { no. of patients }\end{array}$ & $\begin{array}{c}32.6 \pm 82.8 \\
9.4 \pm 19.7 \\
19\end{array}$ & $\begin{array}{c}33.1 \pm 52.2 \\
27.0 \pm 39.1 \\
20\end{array}$ & $\begin{array}{c}16.5 \pm 22.6 \\
2.9 \pm 3.9 \\
20\end{array}$ & $\begin{array}{c}8.7 \pm 12.8 \\
4.9 \pm 6.7 \\
7\end{array}$ \\
\hline $\begin{array}{l}\text { "Values are e } \\
\text { ecidural hemato }\end{array}$ & $\begin{array}{l}\text { sed as me } \\
\therefore \mathrm{SDH}=\mathrm{SL}\end{array}$ & $\begin{array}{l} \pm \text { standard } \\
\text { al hematom }\end{array}$ & vation. Abbre & ations: $\mathrm{EDH}=$ \\
\hline
\end{tabular}

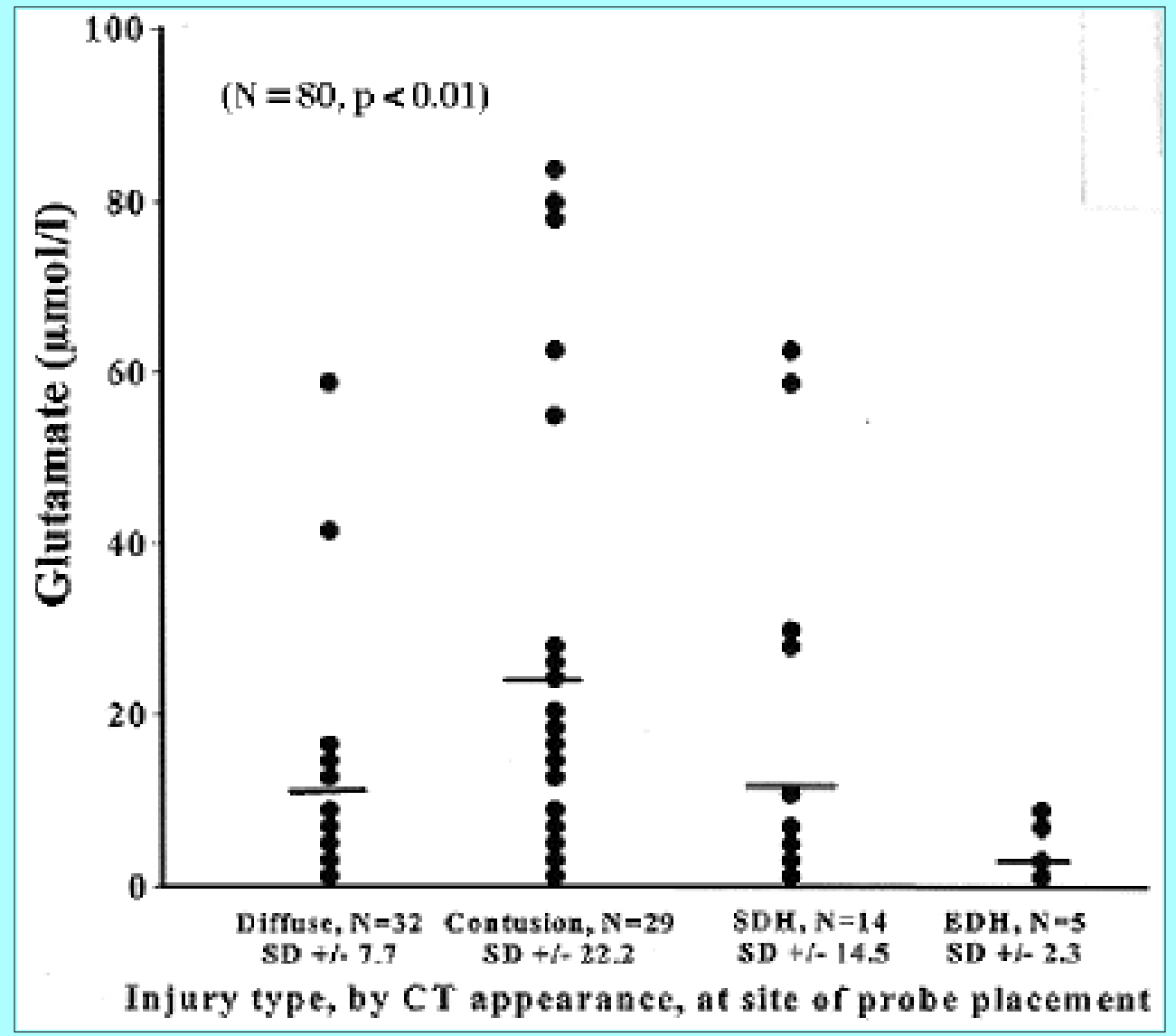

Fig. 5. Scatterplot graph showing the mean levels of dialysate glutamate in the four injury 
subtypes classified by CT scanning. $\mathrm{SD}=$ standard deviation.

The mean EAA data over time for each patient was used and the mean was obtained again for each diagnostic category (the mean of the mean). It is seen that the mean value for glutamate among patients with diffuse injury (with and without superimposed ischemic events) was $14.1 \pm 7.7 \mu \mathrm{mol} / \mathrm{L}$. In patients with subdural or epidural hematomas, levels of EAAs and structural amino acids were not significantly increased when compared with those in patients with diffuse injuries (18 \pm 15 and $3 \pm 3 \mu \mathrm{mol} / \mathrm{L}$, respectively). In patients with contusions, however, the mean glutamate level was $27 \pm 20 \mu \mathrm{mol} / \mathrm{L}$, which was significantly higher than the level for patients with diffuse injuries $(\mathrm{p}<0.01)$. When the clinical course was complicated by hypoxemic or ischemic events, a marked, significant increase in EAA and structural amino acid release was seen to occur. The relationship between ischemic events and dialysate glutamate is shown in Table 4 and Figs. 6 and 7 (see later discussion of this topic).
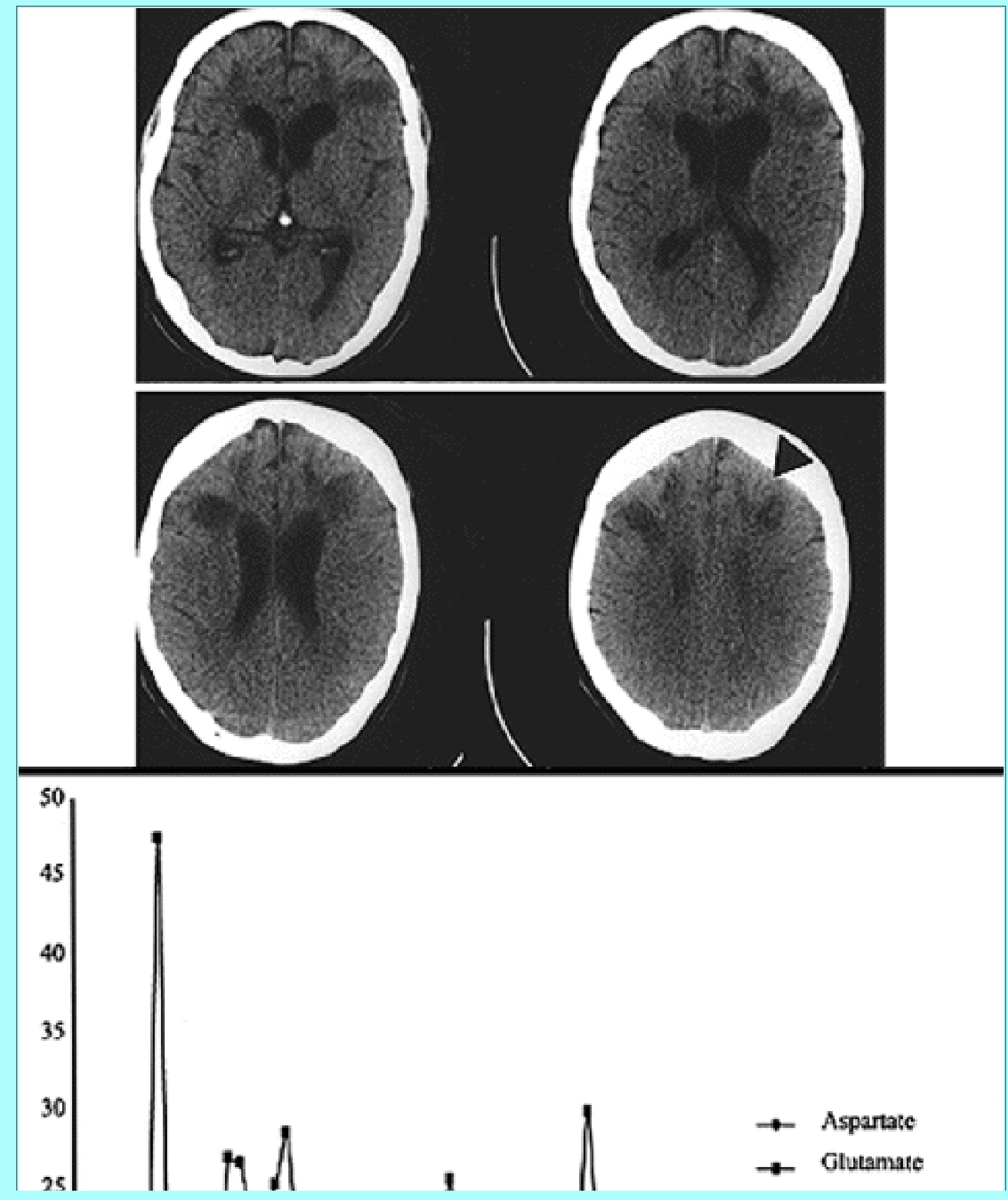


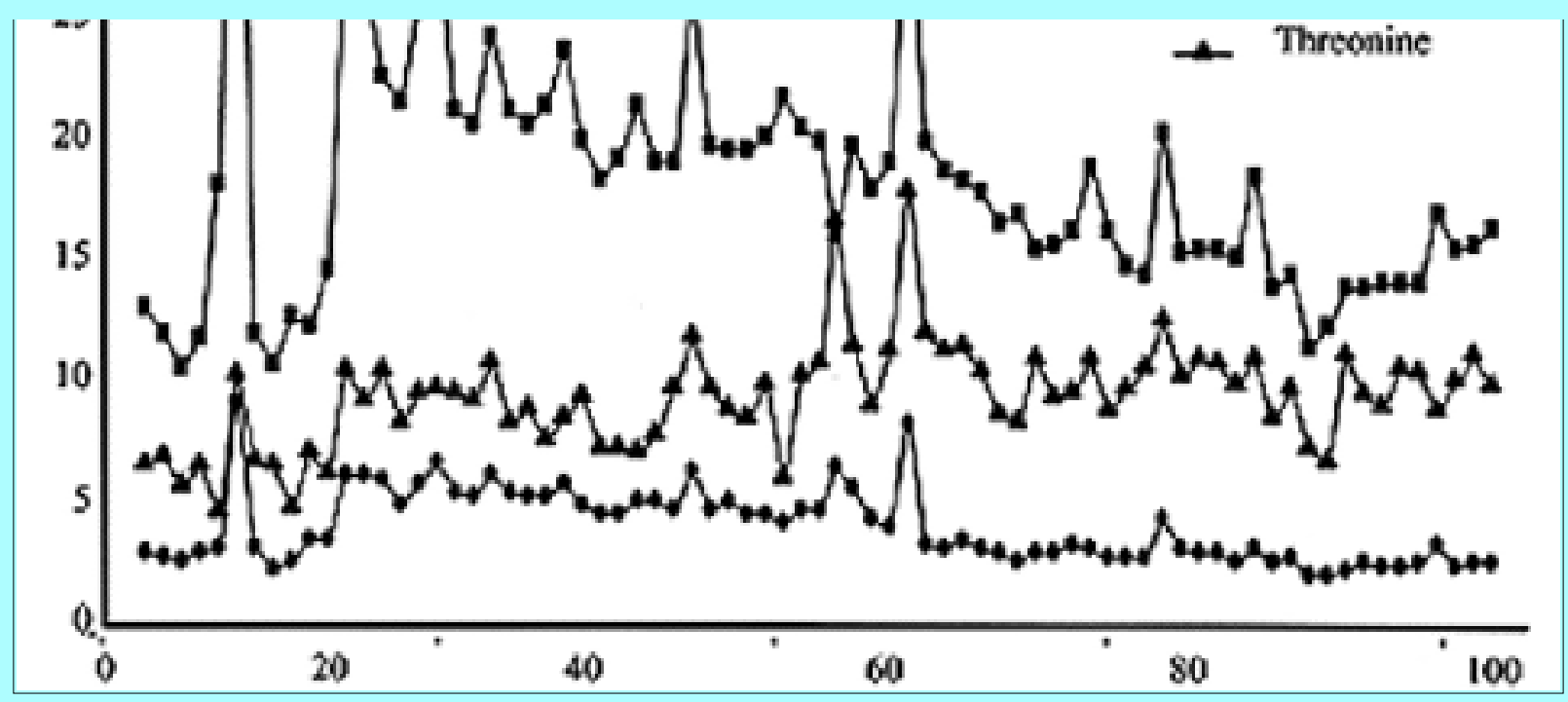

Fig. 6. Data showing the effect of global cerebral ischemia on dialysate EAAs in a 39-year-old patient who sustained bilateral pneumothoraces and retroperitoneal hemorrhage in a "roll-over" motor vehicle accident. The patient was suffering from shock (blood pressure 110/40 $\mathrm{mm} \mathrm{Hg}$ ) and hypoxemia $\left(\mathrm{PaO}_{2} 55 \mathrm{~mm} \mathrm{Hg}\right)$ on arrival in the emergency department. At 1 year the patient had moderate disability. Upper: Computerized tomography scans obtained at 3 months showing a "watershed" infarction (probe site is shown by arrowhead). Lower: Graph showing levels of EAAs, including a 10-fold increase in glutamate over baseline, declining over time.

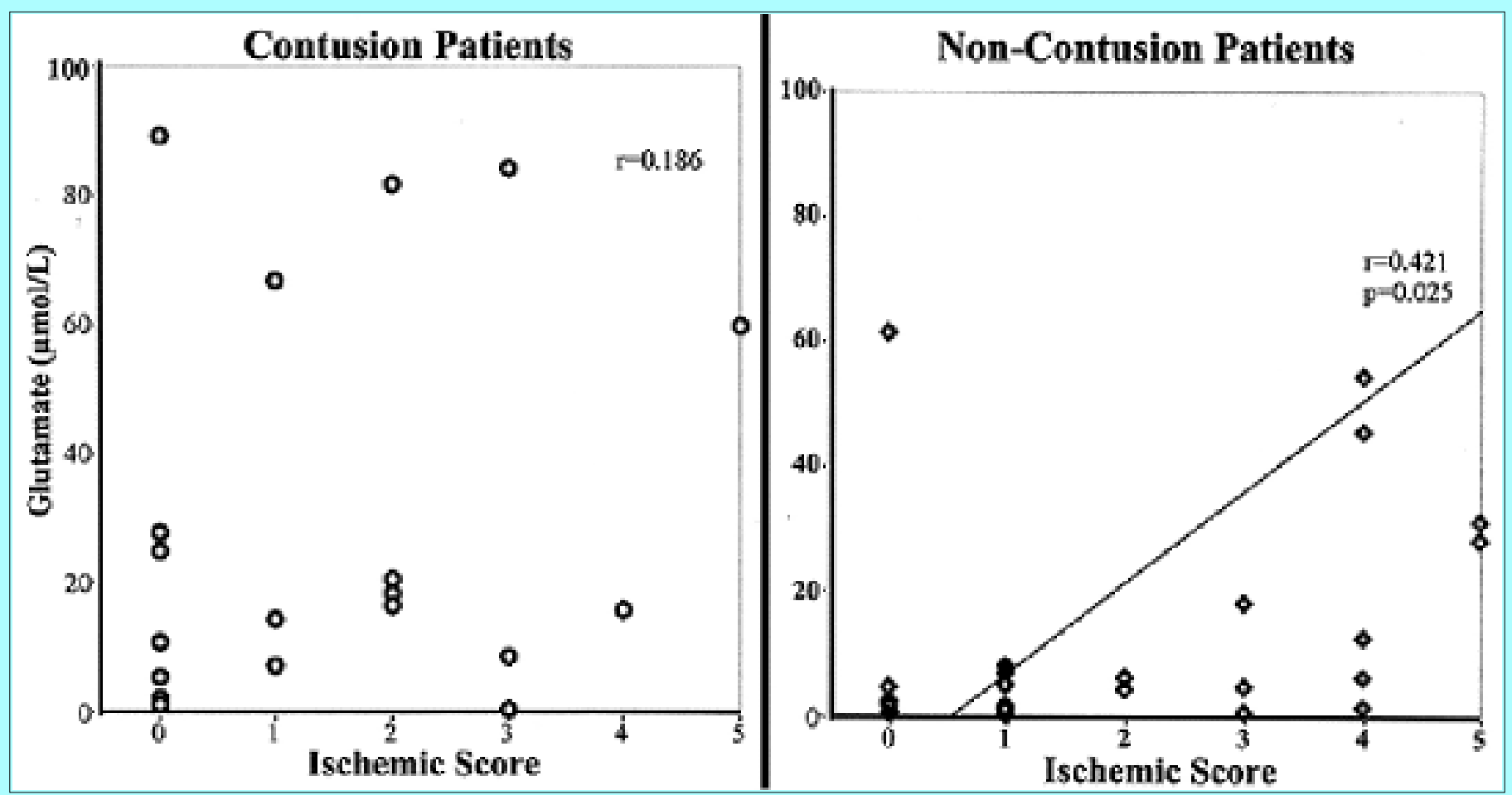

Fig. 7. Graph displaying the relationship between dialysate glutamate and ischemic events in patients with and without focal contusions at the probe site (see Table 1 for description of ischemic events scoring).

\section{Relationship Between EAAs and Clinical Events During Monitoring in the ICU}

The only clinical event that could be identified as exerting a significant influence on dialysate amino acids levels during the ICU monitoring was a sustained increase in ICP, such that CPP fell below approximately 40 to $50 \mathrm{~mm} \mathrm{Hg}$. 
The presence or absence of mild hypoxemia (not below $60 \mathrm{~mm} \mathrm{Hg}$ ), neuromuscular paralysis, ventilator weaning, coma, or fluctuations in core temperature could not be shown to influence amino acid patterns in the dialysate, by inspection of the graphs or by linear regression analysis. However, no patient in this series, except those destined to brain death, developed sustained severe hypoxemia $\left(\mathrm{PaO}_{2}<50 \mathrm{~mm} \mathrm{Hg}\right)$ while in the ICU, and no patient manifested clinical or subclinical seizures as far as we are aware. In one patient, a large intracerebral and subdural hematoma developed in the hemisphere contralateral to the microdialysis probe and was associated with an increase in ICP to $30 \mathrm{~mm} \mathrm{Hg}$. These events did not seem to influence amino acids in the dialysate sampled from the noncompressed hemisphere.

\section{Relationship Between Dialysate EAAs and Ischemic Events}

The presence of ischemic events, before commencement of microdialysis or during monitoring, was the only recorded condition that seemed to influence EAAs in the dialysate. Together with the presence of a focal contusion, it was the major cause of an increase in dialysate EAAs and structural amino acids (Table 4). The highest dialysate EAAs were seen in patients with both ischemic events and focal contusion (Fig. 7). However, in the presence of a contusion, the severity of ischemia was not related to the magnitude of EAA release. In patients in whom the dialysis probe was located away from a focal contusion, however, the dialysate glutamate was linearly correlated with the severity of ischemic events $(r=0.421, p=0.025$; Fig. 7).

\section{Relationship Between Dialysate EAAs and ICP}

The relationship between glutamate and ICP for the entire patient group was found to be significant $(\mathrm{r}=0.554$, $\mathrm{p}<0.01)$. Patients having the highest overall mean glutamate values displayed the most significant correlation with ICP $(r=0.659, p=0.0104)$ in comparison with the two other glutamate categories (Fig. 8). This is also reflected in the relationship between EAAs and ischemic events (Table 4 and Fig. 7). 


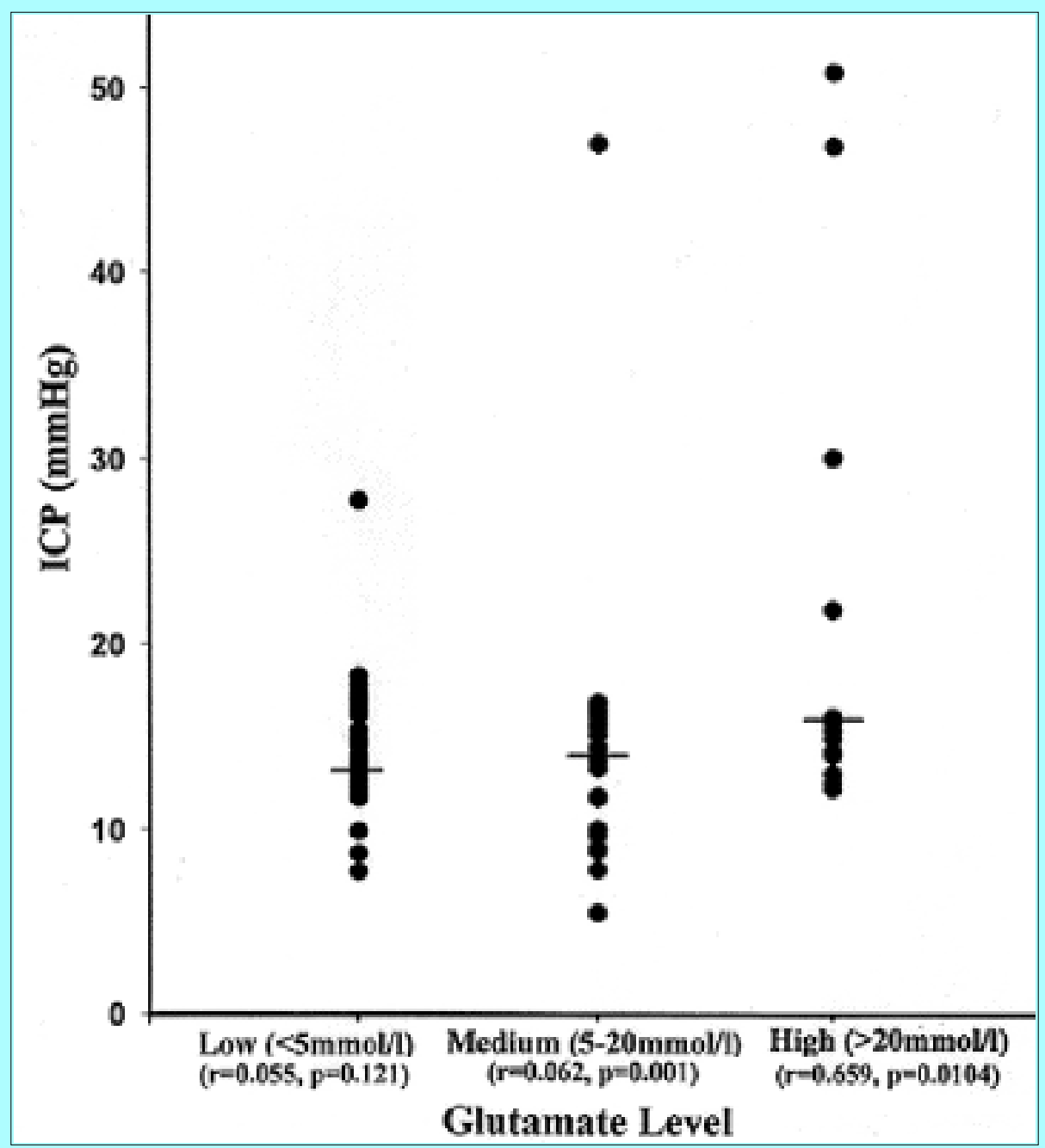

Fig. 8. Scatterplot graph depicting the relationship between mean ICP and dialysate glutamate.

\section{Relationship Between Dialysate EAAs and Outcome}

The relationship between patient outcome and dialysate EAA levels is documented in Table 2 and Fig. 9. A significant correlation was found that demonstrated higher glutamate levels in those patients with unfavorable outcomes $(r=0.33, p<0.05)$. Within the high-glutamate group, however, five $(6 \%)$ of the patients achieved favorable outcomes. Three patients were monitored at the site of contusional damage in the cortex, which has been shown to elevate focal EAA levels dramatically without necessarily compromising the "whole brain" outcome. 


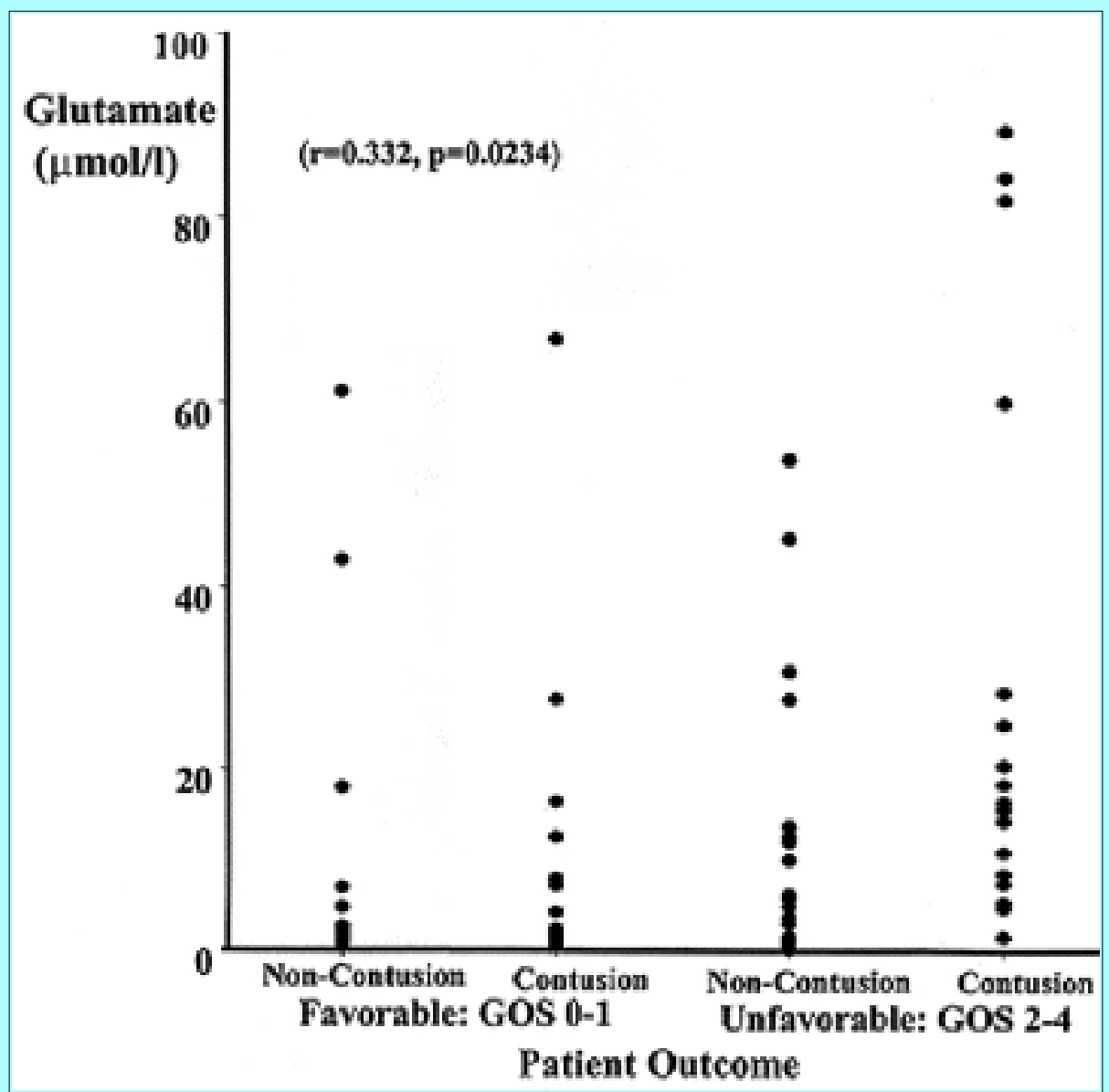

Fig. 9. Scatterplot graph displaying the relationship between dialysate glutamate and outcome for patients in whom the probe was placed in contused and noncontused cerebral tissue. GOS = Glasgow Outcome Scale score.

For the 15 patients in the low-glutamate group who experienced unfavorable outcomes (eight patients died, two are in a vegetative state, and five are severely disabled) without an increase in dialysate EAA levels, the majority experienced secondary or unrelated complications such as pulmonary embolism, deep venous thrombosis, or massive brainstem hematoma, and withdrawal of supportive therapy in the case of an elderly patient in a prolonged vegetative state. These events dramatically worsened these patients' outcomes independently of their EAA levels, measured at a small focal zone.

\section{DISCUSSION}

There are five main findings from this study. 1) Dialysate EAAs were increased to strikingly high levels (up to 50 times normal) in $30 \%$ of patients, and this also correlated well with structural amino acid changes. 2) The increase in EAAs was seen to persist for the duration of monitoring--up to 4 days in most of these patients. 3) The presence of a focal contusion and primary or secondary ischemic events were the clinical features most strongly correlated with high dialysate EAAs. 4) Raised ICP was significantly more common in patients with high dialysate EAAs. 5) Outcome was worse in patients with high levels of dialysate EAAs.

\section{Contusions in the Cortex}

These studies have shown that extracellular amino acids are increased approximately 10 to 20 times higher in contused cortex in comparison with noncontused cortex, and these increases remain throughout the 4-day study period. There is minimal fluctuation in dialysate amino acid levels around contusions over time and the levels are independent of the size of the contusion. These increased levels appear to be independent of changes in ICP or superimposed ischemic events (Fig. 7). Together with the similarity between structural and EAAs, 
this finding suggests that nonspecific destructive processes such as development of membrane cell micropores may be occurring in this contused cortex. However, a major increase in extracellular potassium was not seen in the pericontusional tissue, suggesting that astrocytes may be retaining their potassium-buffering capacity (data reported separately).[10,42] Our previous regional blood flow studies have shown profound reductions in $\mathrm{CBF}$, both within contused cortex and in the pericontusional (edema) zone, as detected by low attenuation on CT scanning. $[4,38,39,47]$ Moreover, these studies have also shown no tendency for improved perfusion over time within these pericontusional zones.

We therefore speculate that neuronal disruption by shearing forces at impact when the contusion occurs leads to development of membrane micropores and leakage of amino acids. Glutamate may then contribute to pericontusional edema and ischemia by inducing the opening of neuronal ion channels to promote potassium efflux and sodium influx. This process is likely to result in astrocytic swelling and neuronal shrinkage. Both these findings have been seen in ultrastructural and light microscopic analysis of biopsied peri-contusional tissue in our previous studies.[1,16]

It is noteworthy that the lowest levels of EAAs were seen in the five patients who had epidural hematomas, even though all of these patients were initially in coma after removal of the hematoma. This suggests that transient brain compression caused by epidural hematoma is sufficient to cause coma, yet not sufficient to damage the brain enough to cause EAA release.

The mean EAA level in the 14 patients with acute subdural hematoma was nine times higher than the "normal value" for the mammalian brain. This accords quite closely with findings in our previous studies in the rat model with acute subdural hematoma, but this EAA rise was not significantly higher than in patients with diffuse injury. This is probably because of the heterogeneity of this group of acute subdural hematoma patients: some sustained secondary ischemic events, whereas others improved to emerge from coma in 3 to 4 days, and made a rapid recovery.

\section{Structural Amino Acids, EAAs, and Causes of Release}

Some aspects of these studies are consistent with the findings of previous animal studies. Studies conducted by Katayama, et al.,[28] Faden, et al.,[17] and our own previous studies have shown brief, transient elevations of EAAs to two to seven times higher than basal levels, persisting only 10 to 30 minutes after impact, in both fluid percussion injury and subdural hematoma in the rat. $[6,8,12]$

Animal studies have only assessed events over a few hours before and after impact. In contrast, these human studies have only captured data for the postimpact period, ranging from 3 hours to 6 days after impact. Extrapolating our human data closer to the time of impact, we speculate that human TBI is associated with much higher magnitudes of transient EAA release than those found in animal models. The typical pattern of amino acid efflux seen in patients without significant secondary ischemic events (Fig. 2) and the early fall in EAA levels support the conclusion that an "ictal surge" of EAAs occurs in human TBI, as well as in animal models.

Amino acid levels in certain patients who suffered major secondary insults were up to 50 times higher than normal levels. In most patients who did not have secondary ischemic events, levels of both EAAs and structural amino acids remained constant or declined and fluctuated by only 10 to $20 \%$ of the initial values throughout the monitoring period. In those patients who died, however, steadily increasing EAA and structural amino acid levels were usually seen, suggesting ongoing release by one or more mechanisms. Elsewhere, we have reported a close correlation between high glutamate $(>20 \mu \mathrm{mol} / \mathrm{L})$ and regional CBF levels below 18 $\mathrm{ml} / 100 \mathrm{~g} /$ minute.[27,57]

These studies have shown massive increases (up to 50-fold) in both EAAs and structural amino acid 
concentrations in brain extracellular fluid dialysate in certain categories of patients who have sustained severe head injury, whereas in others, levels of amino acids remain normal or near normal. Although the microdialysis technique is only capable of sampling events within a relatively small volume of cortex (approximately 10-20 $\mathrm{mm}$ around the dialysis probe) these studies have shown that the type of intracranial lesion observed on CT scanning and the presence or absence of a significant secondary ischemic event are the major determinants of amino acid release. In contrast, the patterns of amino acid release over time were remarkably constant in individual patients and were not influenced by transient clinical events such as a brief increase in ICP. Increased levels of dialysate amino acids, however, were significantly associated with bad outcome and with prolonged, severely raised ICP in this study.

With regard to the hypothesis we have attempted to test in this study, we have clearly confirmed the first and the third points, namely that EAA release is clearly a major event after human TBI, especially focal contusion, and that EAA release is exacerbated markedly in ischemic secondary events, as seen in animal model studies.[20,32] As yet, however, our data do not allow us to confirm or refute our second hypothesis, namely that high EAA levels cause posttraumatic brain damage. This study does provide three lines of reasoning to support the concept that EAA release after human TBI does cause brain damage in some patients. First, an association was seen between increased EAAs and high ICP (Table 2 and Figs. 4 and 8). This accords with the concept that EAAs open ion channels to cause cell swelling and cell death.[37,42,43,46] Second, in vitro studies show that prolonged exposure of postsynaptic receptors to very high concentrations of glutamate (50-100 mol/L) in mixed cell cultures, for periods as short as a few hours, will kill neurons.[13,20,42] Our studies show that approximately $30 \%$ of our patients with severe TBI manifested glutamate levels in the extracellular fluid that were at least double this concentration over many days. Third, the fact that these high dialysate concentrations are sustained for up to several days, in marked contrast with animal models, suggests that glutamate uptake mechanisms in presynaptic dendritic membranes and in astrocytes are nonfunctional, thus allowing such pathologically high EAA levels to persist in the extracellular fluid.[41] The role of neurotrauma in inactivating these "intrinsically neuroprotective" glutamate reuptake mechanisms requires further study.

The clearest implication of this study for future therapy of head-injured patients concerns the use of EAA antagonist drugs. Currently, at least six glutamate antagonists of different types are in clinical testing for different indications, including severe head injury.[5,7,37] However these agents carry an important side-effect profile, including effects such as hallucinations, paranoia, agitation, and sedation. This study suggests that, for the majority of patients in a coma after head injury who have a normal CT scan appearance and have not sustained secondary ischemic events, prolonged therapy with a glutamate antagonist is probably not warranted. A single dose administered as soon as possible after the injury may be sufficient to blunt the consequences of the immediate injury-related surge in EAAs, which has been shown in animal models.[20,21,24,25,32,35,40,44, 48,55] However, it is also clear from this study that patients with focal cerebral contusions and those with secondary ischemic events such as low CPP, raised ICP, hypoxemia, or reduced $\mathrm{CBF}$ would benefit from therapy with these agents for at least 4 days or more. Studies focusing on even later time points postinjury are needed to determine the longer time course of these events.

\section{Acknowledgments}

We are grateful to the neurosurgery residents and neuroscience nurses at Medical College of Virginia, who made this study happen by helping our research group in every way possible. Melody Rice, M.S., Osamu Tsuji, M.D., and Jana Dunbar, M.S., assisted with in vitro experiments, for which we are also very grateful. Steve Koura assisted with data entry.

\section{References}


1. Adams JH, Graham DI, Gennarelli TA: Head injury in man and experimental animals: neuropathology. Acta Neurochir (Suppl 32):15-30, 1983

2. Becker DP, Katayama Y, Tamura T, et al: Excitotoxic ion fluxes and neuronal dysfunction following traumatic brain injury. J Cereb Blood Flow Metab 9 (Suppl 1):S302, 1989 (Abstract)

3. Benveniste H, Drejer J, Schousboe A, et al: Elevation of the extracellular concentrations of glutamate and aspartate in rat hippocampus during transient cerebral ischemia monitored by intracerebral microdialysis. $\mathbf{J}$ Neurochem 43:1369-1374, 1984

4. Bouma GJ, Muizelaar JP, Stringer WA, et al: Ultra-early evaluation of regional cerebral blood flow in severely head-injured patients using xenon-enhanced computerized tomography. J Neurosurg 77:360-368, 1992

5. Bullock R: Opportunities for neuroprotective drugs in clinical management of head injury. J Emerg Med 11 (Suppl 1):23-30, 1993

6. Bullock R, Butcher SP, Chen MH, et al: Correlation of extracellular glutamate concentration with extent of blood flow reduction after subdural hematoma in the rat. J Neurosurg 74:794-801, 1991

7. Bullock R, Fujisawa H: The role of glutamate antagonists for the treatment of CNS injury. J Neurotrauma 9 (Suppl 2):5443-5462, 1992

8. Bullock R, Inglis FM, Kuroda Y, et al: Transient hippocampal hypermetabolism associated with glutamate release after acute subdural haematoma in the rat: a potentially neurotoxic mechanism. J Cereb Blood Flow Metab 11 (Suppl 2):S109, 1991 (Abstract)

9. Bullock R, Zauner A, Tsuji O, et al: Excitatory amino acid release after severe human head trauma: effect of intracranial pressure and cerebral perfusion pressure changes, in Nagai H, Kamiya K, Ishii S (eds):

Intracranial Pressure IX. Tokyo: Springer-Verlag, 1994, pp 264-267

10. Bullock R, Zauner A, Tsuji O, et al: Patterns of excitatory amino acid release and ionic flux after severe head trauma, in Tsubokawa T, Marmarou A, Robertson C, et al (eds): Neurochemical Monitoring in the Intensive Care Unit. Tokyo: Springer-Verlag, 1995, pp 64-67

11. Butcher SP, Bullock R, Graham DL, et al: Correlation between amino acid release and neuropathologic outcome in rat brain following middle cerebral artery occlusion. Stroke 21:1727-1733, 1990

12. Chen MH, Bullock R, Graham DI, et al: Ischemic neuronal damage after acute subdural hematoma in the rat: effects of pretreatment with a glutamate antagonist. J Neurosurg 74:944-950, 1991

13. Choi DW, Maulucci-Gedde M, Kriegstein AR: Glutamate neurotoxicity in cortical cell culture. J Neurosci 7:357-368, 1987

14. Choi SC, Chinchilli VM: Analysis of within- and across-subject correlations, in Bozdogan H, Gupta AK (eds): Multivariate Statistical Modeling and Data Analysis. Dordrecht: Reidel, 1989, pp 77-94

15. During MJ, Spencer DD: Extracellular hippocampal glutamate and spontaneous seizure in the conscious human brain. Lancet 341:1607-1610, 1993

16. Erb DE, Povlishock JT: Axonal damage in severe traumatic brain injury: an experimental study in the cat. Acta Neuropathol 76:347-358, 1988

17. Faden AI, Demediuk P, Panter SS, et al: The role of excitatory amino acids and NMDA receptors in 
traumatic brain injury. Science 244:798-800, 1989

18. Gentleman D, Jennett B: Hazards of inter-hospital transfer of comatose head injured patients. Lancet 2:853-855, 1981

19. Graham DI, Lawrence AE, Adams JH, et al: Brain damage in fatal non-missile head injury without high intracranial pressure. J Clin Pathol 41:34-37, 1988

20. Hayes RL, Jenkins LW, Lyeth BG, et al: Pretreatment with phencyclidine, an N-methyl-D-aspartate antagonist, attenuates long-term behavioral deficits in the rat produced by traumatic brain injury. $\mathbf{J}$

Neurotrauma 5:259-274, 1988

21. Heiss WD, Hayakawa T, Waltz AG: Cortical neuronal function during ischemia. Effects of occlusion of one middle cerebral artery on single-unit activity in cats. Arch Neurol 33:813-820, 1976

22. Hillered L, Hallström A, Segersvärd S, et al: Dynamics of extracellular metabolites in the striatum after middle cerebral artery occlusion in the rat monitored by intracerebral microdialysis. J Cereb Blood Flow Metab 9:607-616, 1989

23. Hillered L, Persson L, Carlson H, et al: Studies on excitatory amino acid receptor-linked brain disorders in rat and man using in vivo microdialysis. Clin Neuropharmacol 15 (Suppl 1, Part A):695A-696A, 1992

24. Inglis F, Kuroda Y, Bullock R: Glucose hypermetabolism after acute subdural hematoma is ameliorated by a competitive NMDA antagonist. J Neurotrauma 9:75-84, 1992

25. Jenkins LW, Lyeth BG, Lewelt W, et al: Combined pretrauma scopolamine and phencyclidine attenuates posttraumatic increased sensitivity to delayed secondary ischemia. J Neurotrauma 5:275-287, 1988

26. Jenkins LW, Moszynski K, Lyeth BG, et al: Increased vulnerability of the mildly traumatized rat brain to cerebral ischemia: the use of controlled secondary ischemia as a research tool to identify common or different mechanisms contributing to mechanical and ischemic brain injury. Brain Res 477:211-224, 1989

27. Jones TH, Morawetz RB, Crowell RM, et al: Thresholds of focal cerebral ischemia in awake monkeys. J Neurosurg 54:773-782, 1981

28. Katayama Y, Becker DP, Tamura T, et al: Massive increases in extracellular potassium and the indiscriminate release of glutamate following concussive brain injury. J Neurosurg 73:889-900, 1990

29. Kawamata T, Katayama Y, Hovda D, et al: Administration of excitatory amino acid antagonists via microdialysis attenuates the increase in glucose utilization seen following concussive brain injury. J Cereb Blood Flow Metab 12:12-24, 1992

30. Kirino T, Tamura A, Sano K: Delayed neuronal death in the rat hippocampus following transient forebrain ischemia. Acta Neuropathol 64:139-147, 1984

31. Kotapka MJ, Graham DI, Adams JH, et al: Hippocampal pathology in fatal non-missile human head injury. Acta Neuropathol 83:530-534, 1992

32. Kuroda Y, Fujisawa H, Strebel S, et al: Effect of neuroprotective N-methyl-D-aspartate antagonists on increased intracranial pressure: studies in the rat acute subdural hematoma model. Neurosurgery 35:106-112, 1994

33. Lyeth BG, Jenkins LW, Hamm RJ, et al: Pretreatment with MK-801 reduces behavioral deficits following traumatic brain injury in rats. Soc Neurosci 15:1113, 1989 (Abstract) 
34. Lindroth P, Mopper K: High performance liquid chromatographic determination of sub-picomole amounts of amino acids by precolumn fluorescence derivatization with o-pthaldialdehyde. Anal Chem 51:1667-1674, 1979

35. McIntosh TK, Vink R, Soares H, et al: Effect of noncompetitive blockade of N-methyl-D-aspartate receptors on the neurochemical sequelae of experimental brain injury. J Neurochem 55:1170-1179, 1990

36. McIntosh TK, Vink R, Soares H, et al: Effects of the N-methyl-D-aspartate receptor blocker MK-801 on neurologic function after experimental brain injury. J Neurotrauma 6:247-259, 1989

37. Meldrum B: Protection against ischaemic neuronal damage by drugs acting on excitatory neurotransmission. Cerebrovasc Brain Metabol Rev 2:27-57, 1990

38. Meyer JS, Hayman LA, Yamamoto M, et al: Local cerebral blood flow measured by CT after stable xenon inhalation. AJR 135:239-251, 1980

39. Muizelaar JP, Schröder ML: Overview of monitoring of cerebral blood flow and metabolism after severe head injury. Can J Neurol Sci 21 (Suppl):1-6, 1994

40. Nehls DG, Park CK, MacCormack AG, et al: The effects of N-methyl D-aspartate receptor blockade with MK-801 upon the relationship between cerebral blood flow and glucose utilization. Brain Res 511:271-279, 1990

41. Nicholls D, Attwell D: The release and uptake of excitatory amino acids. Trends Pharmacol Sci 11:462-468, 1990

42. Nilsson P, Hillered L, Olsson Y, et al: Regional changes in interstitial $\mathrm{K}^{+}$and $\mathrm{Ca}^{2+}$ levels following cortical compression contusion trauma in rats. J Cereb Blood Flow Metabol 13:183-192, 1993

43. Nilsson P, Hillered L, Pontén U, et al: Changes in cortical extracellular levels of energy-related metabolites and amino acids following concussive brain injury in rats. J Cereb Blood Flow Metab 10:631-637, 1990

44. Persson L, Hillered L: Chemical monitoring of neurosurgical intensive care patients using intracerebral microdialysis. J Neurosurg 76:72-80, 1992

45. Ronne-Engström E, Hillered L, Flink R, et al: Intracerebral microdialysis of extracellular amino acids in the human epileptic focus. J Cereb Blood Flow Metab 12:873-876, 1992

46. Rothman SM, Olney JW: Excitotoxicity and the NMDA receptor. Trends Neurosci 10:299-302, 1987

47. Schröder ML, Muizelaar JP, Kuta AJ: Documented reversal of global ischemia immediately after removal of acute subdural hematoma. Report of two cases. J Neurosurg 80:324-327, 1994

48. Shapira Y, Yadid G, Cotev S, et al: Protective effect of MK801 in experimental brain injury. J Neurotrauma 7:131-139, 1990

49. Shimada N, Graf R, Rosner G, et al: Differences in ischemia-induced accumulation of amino acids in the cat cortex. Stroke 21:1445-1451, 1990

50. Shimada N, Graf R, Rosner G, et al: Ischemia-induced accumulation of extracellular amino acids in cerebral cortex, white matter, and cerebrospinal fluid. J Neurochem 60:66-71, 1993

51. Shiraishi K, Sharp FR, Simon RP: Sequential metabolic changes in rat brain following middle cerebral 
artery occlusion: a 2-deoxyglucose study. J Cereb Blood Flow Metab 9:765-773, 1989

52. Smith DH, Okiyama K, McIntosh T: Ketamine and magnesium attenuates memory loss after experimental brain injury. Soc Neurosci 17:167, 1991 (Abstract)

53. Smith DH, Okiyama K, Thomas M, et al: The effects of two novel NMDA antagonists on regional cation concentration and edema formation following experimental brain injury. J Cereb Blood Flow Metab 11 (Suppl 2):S300, 1991 (Abstract)

54. Smith DH, Okiyama K, Thomas M, et al: An NMDA receptor-associated glycine site antagonist attenuates memory loss after experimental brain injury. Soc Neurosci 2:779, 1990 (Abstract)

55. Smith DH, Thomas M, Soares H, et al: Differential effects of competitive and non-competitive N-methyl-D-aspartate (NMDA) antagonists following experimental brain injury. J FASEB 4:400, 1990 (Abstract)

56. Takizawa S, Hogan M, Hakim AM: The effects of a competitive NMDA receptor antagonist (CGS-19755) on cerebral blood flow and pH in focal ischemia. J Cereb Blood Flow Metab 11:786-793, 1991

57. Zauner A, Bullock R, Kuta AJ, et al: Glutamate release and cerebral blood flow after severe human head injury. Acta Neurochir Suppl 67:40-44, 1996

58. Zauner A, Doppenberg EMR, Woodward JJ, et al: Continuous monitoring of cerebral substrate delivery and clearance: initial experience in 24 patients with severe acute brain injuries. Neurosurgery 41:1082-1093, 1997

Manuscript received February 27, 1998.

Accepted in final form June 2, 1998.

These studies were funded by National Institutes of Health Grant No. NS12587.

Address reprint requests to: Ross Bullock, M.D., Ph.D., Division of Neurosurgery, Medical College of Virginia, P. O. Box 980631, Richmond, Virginia 23298. 